\title{
Effects of a putrescine analog on Giardia lamblia
}

\author{
C. Maia • A. Lanfredi-Rangel • K. G. Santana-Anjos • \\ M. F. Oliveira - W. De Souza • M. A. Vannier-Santos
}

Received: 14 January 2008 / Accepted: 31 March 2008/Published online: 24 April 2008

(C) Springer-Verlag 2008

\begin{abstract}
The protozoan Giardia lamblia is the most frequent intestinal parasite of first-world countries and a major cause of waterborne disorder often referred to as traveler's diarrhea. We have previously noticed that the putrescine analog 1,4-diamino-2-butanone (DAB) remarkably inhibits the growth of anaerobic trichomonad and Trypanosoma cruzi parasites. Here, we examined the role of polyamines in Giardia cells using this putrescine analog. DAB impaired parasite proliferation dose-dependently.
\end{abstract}

\footnotetext{
C. Maia $\cdot$ W. De Souza

Instituto de Biofísica Carlos Chagas Filho,

Universidade Federal do Rio de Janeiro,

Rio de Janeiro, RJ, Brazil

C. Maia

e-mail: cmaia@biof.ufrj.br

W. De Souza

e-mail: wsouza@biof.ufrj.br

A. Lanfredi-Rangel $\cdot$ K. G. Santana-Anjos ·

M. A. Vannier-Santos $(\bowtie)$

Centro de Pesquisas Gonçalo Moniz Fundação Oswaldo Cruz,

Rua Waldemar Falcão 121, Candeal,

Salvador 40296-710 Bahia, Brazil

e-mail: vannier@bahia.fiocruz.br

A. Lanfredi-Rangel

e-mail: alrangel@bahia.fiocruz.br

K. G. Santana-Anjos

e-mail: karlagraziela@gmail.com

M. F. Oliveira

Instituto de Bioquímica Médica,

Universidade Federal do Rio de Janeiro,

Rio de Janeiro, RJ, Brazil

e-mail: maroli@bioqmed.ufrj.br
}

The analog induced increased flagella numbers and sometimes four ventral disks as well as asymmetrical division, indicating truncated or deregulated cytokinesis. Electron microscopy analysis revealed that $\mathrm{DAB}$ also triggered the encystment process. Oxidative stress was evaluated by measuring lipid peroxidation by thiobarbituric acid reactive substances (TBARS) detection. Trophozoites incubated either with $1 \mathrm{mM}$ of DAB or putrescine for $18 \mathrm{~h}$ displayed increased lipoperoxide levels. Addition of $200 \mu \mathrm{M}$ aminoguanidine, a polyamine/diamine oxidase inhibitor, partially reverted the $\mathrm{DAB}$, but not the putrescine effects, indicating that the DAB effects are due, at least in part, to $\mathrm{DAB}$ oxidation end products. These data indicate that polyamines play a role in Giardia cell division, differentiation, and antioxidant defenses.

$\begin{array}{ll}\text { Abbreviations } \\ \text { DAB } & \text { 1,4-diamino-2-butanone } \\ \text { AG } & \text { aminoguanidine } \\ \text { TBA } & \text { thiobarbituric acid } \\ \text { TBARS } & \text { thiobarbituric acid reactive substances }\end{array}$

\section{Introduction}

The microaerophilic lumen-dwelling protozoan Giardia lamblia (syn. G. intestinalis, G. duodenalis) is the major cause of parasitic waterborne diarrheal outbreaks with about 280 million clinical annual cases worldwide reported by WHO (Upcroft and Upcroft 2001; Lloyd et al. 2002). Despite comprising a common cause of outbreaks in developed countries such as the US and Canada (Petri 2000), 
giardiasis is regarded as a "neglected disease" (Savioli et al. 2006). The importance of this disease of global incidence is further highlighted by the malabsorption syndrome which causes stunting and cognitive impairment particularly among children (Berkman et al. 2002; reviewed by Farthing 2002; Ali and Hill 2003; Partovi et al. 2007).

Infections may range from asymptomatic, mainly in adults, to severe steatorrhoea mostly in children (Lengerich et al. 1994). The pathophysiological processes of giardiasis was not fully elucidated, but previous studies have reported shortening of the intestinal villi and covering of epithelium microvilli by rapidly proliferating trophozoites, resulting in reduced absorption area with impaired electrolyte and nutrient transport (Gorowara et al. 1992; Scott et al. 2002).

The 5-nitroimidazole metronidazole is first-line drug of choice not only for giardiasis, but also for amebiasis, trichomoniasis, and infections caused by different anaerobic bacteria (Nash 2001; Bansal et al. 2006; Nanda et al. 2006). It is among the most commonly prescribed drugs, extensively employed since the 1950 s, therefore refractory cases are rising, and circa $21 \%$ of the French giardial isolates present some degree of resistance (Lemée et al. 2000; Upcroft and Upcroft 2001). In addition, metronidazole is mutagenic and potentially carcinogenic for humans (Goldman 1980; Bendesky et al. 2002) and therefore search for new giardicidal compounds is required.

Polyamines such as putrescine, spermidine, and spermine are low molecular weight organic polycations involved in cell multiplication and differentiation, as cofactors for the macromolecule synthesis and functioning (Stimac and Morris 1987; Taylor et al. 1988;). These molecules also play important roles protecting membranes and nucleic acids from oxidative stress (Tabor and Tabor 1984), which may be caused by prooxidant compounds (Bellé et al. 2004; Turrens 2004).

Putrescine reaches high levels in anaerobic parasites such as G. lamblia, Trichomonas vaginalis, (Yarlett 1988) and Entamoeba histolytica (Gillin et al. 1984). In most cells, synthesis occurs by the decarboxylation of ornithine to putrescine by ornithine decarboxylase (ODC). Ornithine may also be used for the polyamine synthesis, but the Giardia ODC activity is relatively low, compared to the arginine dihydrolase pathway, and little is known about the biological roles of putrescine, spermidine, or spermine in this parasitic protozoan (Schofield et al. 1990). The DL$\alpha$-difluoromethylornithine (DFMO; Eflornithine ${ }^{\circledR}$ ), an irreversible ODC inhibitor, was developed for cancer therapy (Tabor and Tabor 1976) and shown to have microbicidal activity against African trypanosomes, becoming the drug of choice for sleeping sickness (Bacchi and Yarlett 2002). DFMO also inhibits in vitro growth of G. lamblia, but was ineffective against other extracellular parasites such as $T$. vaginalis and E. histolytica (Gillin et al. 1984).
Polyamine biosynthetic pathways furnish important chemotherapy targets, and its analogs comprise a powerful arsenal against parasitic diseases (Muller et al. 2001; Bacchi and Yarlett 2002).

Polyamine analogs have been developed and tested against different pathogens, but most studies focused on trypanosomatid parasites, and the role of polyamines in anaerobic protozoa remains largely overlooked. The putrescine analog, 1,4-diamino-2-butanone (DAB), was reported to be effective against DFMO-resistant parasites even in complex media (Calvo-Mendez et al. 1993; Reis et al. 1999).

We have previously noticed that DAB inhibits the growth of anaerobic trichomonad parasite Tritrichomonas foetus (Reis et al. 1999) and T. cruzi (Menezes et al. 2006), but little is known about the role of putrescine in Giardia cell biology. Here, we examined the effects of DAB in $G$. lamblia trophozoite proliferation, differentiation, ultrastructure, and oxidative stress.

\section{Materials and methods}

Chemicals 1,4-Diamino-2-butanone aminoguanidine and the polyamine putrescine were purchased from Sigma Chemical Co. (St. Louis, MO, USA). Stock solutions were stored at $-20^{\circ} \mathrm{C}$. All reagents were of analytical grade.

Parasites The Portland-1 (ATCC no. 30888) strain of $G$. lamblia was cultivated in TYI-S-33 medium supplemented with $10 \%$ bovine serum at $37^{\circ} \mathrm{C}$ (Keister 1983). Parasites were harvested by centrifugation after chilling on ice for approximately $10 \mathrm{~min}$. Cell density was determined by counting under light microscopy on Neubauer chamber. Growth assays were performed with a $2.0 \times 10^{5}$ cells $/ \mathrm{mL}$ inoculum.

Transmission electron microscopy Parasites were fixed in 4\% paraformaldehyde (Polysciences), 1\% glutaraldehyde (Polysciences), 4\% sucrose in $0.1 \mathrm{M}$ sodium cacodylate buffer, $\mathrm{pH} 7.2$, postfixed in $1 \%$ osmium tetroxide (Polysciences) and $0.08 \%$ potassium ferricyanide in the same buffer, dehydrated in acetone series, and embedded in Polybed resin (Polysciences). Thin sections were stained with uranyl acetate and lead citrate and observed under a Zeiss 900 transmission electron microscope (TEM).

Scanning Electron Microscopy Samples were fixed and postfixed as described above, dehydrated in ethanol series, dried by the critical point method in a Balzers apparatus, mounted on stubs, and covered with a $20 \mathrm{~nm}$-thick gold layer. Specimens were observed in a JEOL 5310 scanning electron microscope (SEM). 
Lipid peroxidation Trophozoites were washed twice by centrifugation at $500 \times \mathrm{g}$ for $15 \mathrm{~min}$ in phosphate-buffered saline (PBS), $\mathrm{pH}$ 7.2. After centrifugation, $200 \mu \mathrm{L}$ of $0.1 \%$ thiobarbituric acid (TBA) were added to $200 \mu \mathrm{L}$ of cell suspension and incubated at $100^{\circ} \mathrm{C}$ for $3 \mathrm{~h}$. Thiobarbituric acid reactive substances (TBARS) produced were measured at $532 \mathrm{~nm}$ using TBA in PBS as standard.

\section{Results}

Parasite proliferation

A remarkable and sustained (Fig. 1a) dose-dependent (Fig. 1b) inhibition of parasite proliferation was observed in DAB-treated parasites. Drug-induced alterations in cell architecture were analyzed by SEM. Contrary to control dividing cells (Fig. 1c), mitotic trophozoites exposed to DAB presented increased flagella numbers, and sometimes four ventral disks could be observed (Fig. 1d). Abnormal ventral disk disposition was commonly observed after DAB treatment. The large number of cells undergoing incomplete (Fig. 1) and asymmetric (Fig. 2a-d) division processes indicate that the antigiardial effect may be attributed, at least in part, to the impaired or deregulated cytokinesis.
Giardial differentiation

In the early phase of culture, the parasite cytoplasm often presented encystment clefts and vesicles (Fig. 3a,b). Surface protrusions assessed by SEM suggest extrusion of such vesicles at parasite surface (Fig. 3c). Ventral disk internalization was also observed by SEM (Fig. 3d). TEM analysis of the DAB-treated trophozoites revealed the disassembly and internalization of flagella (Fig. 3e) and ventral disk cytoskeleton (Fig. 3f) after $24 \mathrm{~h}$ of treatment. Formation of a loose, slender cyst wall was detected in some DAB-treated cells (Fig. 3e,f).

\section{Oxidative stress}

To evaluate the oxidative stress in DAB-treated trophozoites, we measured lipid peroxidation by the TBARS method. Parasites incubated with $1 \mathrm{mM}$ of DAB for $18 \mathrm{~h}$ displayed significantly increased lipoperoxide levels (Fig. 4). Putrescine not only did not revert this effect, but also increased the levels of peroxidation in Giardia, (not shown). The addition of $200 \mu \mathrm{M}$ aminoguanidine, a diamine/polyamine oxidase inhibitor, partially reverted the DAB (Fig. 4), but not the putrescine effects (not shown).
Fig. 1 1,4-diamino-2-butanone (DAB) remarkably inhibited $G$. lamblia $\mathrm{P} 1$ strain trophozoites in vitro proliferation in TYI-S33 medium supplemented with $10 \%$ FCS (a). Parasites were incubated with increasing $\mathrm{DAB}$ concentrations $(0.1$ to $10 \mathrm{mM})$. The inhibitory effect of the analog was dose-dependent in the concentration range tested (b). Contrary to the stepwisely dividing untreated control cells (c), DAB-treated parasites observed under scanning electron microscopy presented gross alterations in morphology including increased flagella number (arrowheads) and impaired septation process as trophozoites presenting four ventral disks $(V D)$ were observed (d). Note that DABtreated dividing cells formed an angle of roughly $60^{\prime}$ compared to the nearly $180^{\prime}$ in control cells. $\times 5,000$ a
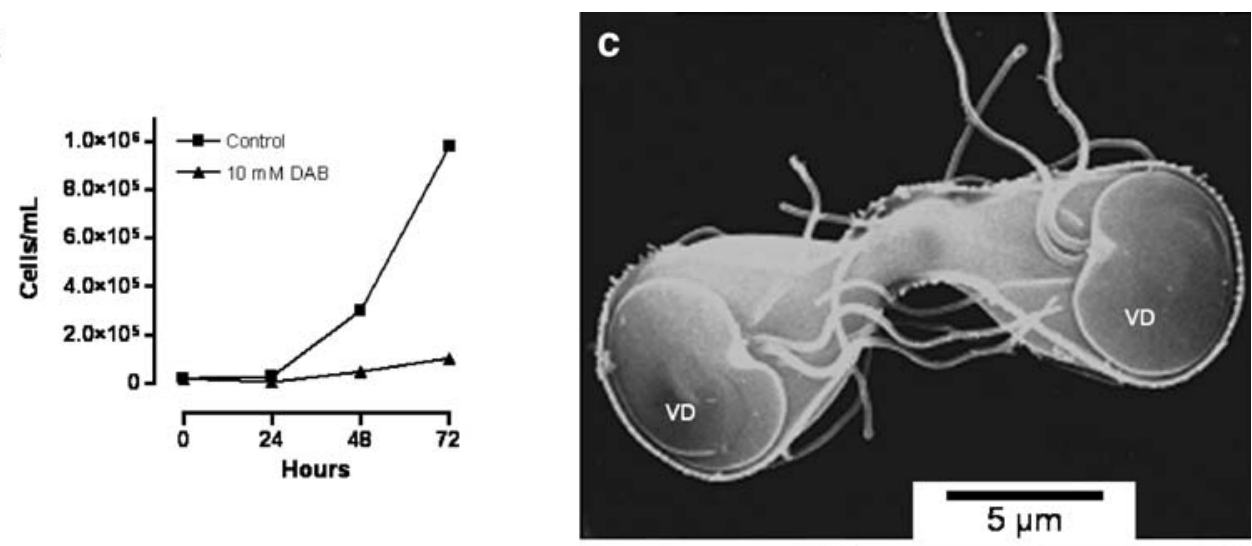

b

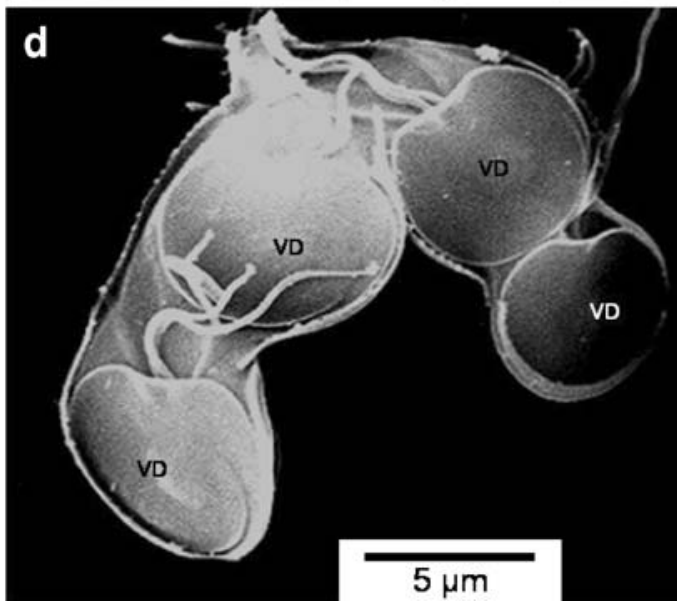


Fig. 2 Contrary to symmetrically dividing untreated control cells (vide Fig. 1c), DAB-treated parasites displayed asymmetrical mitosis both laterally $(\mathbf{a}-\mathbf{c})$ and dorsally (d)
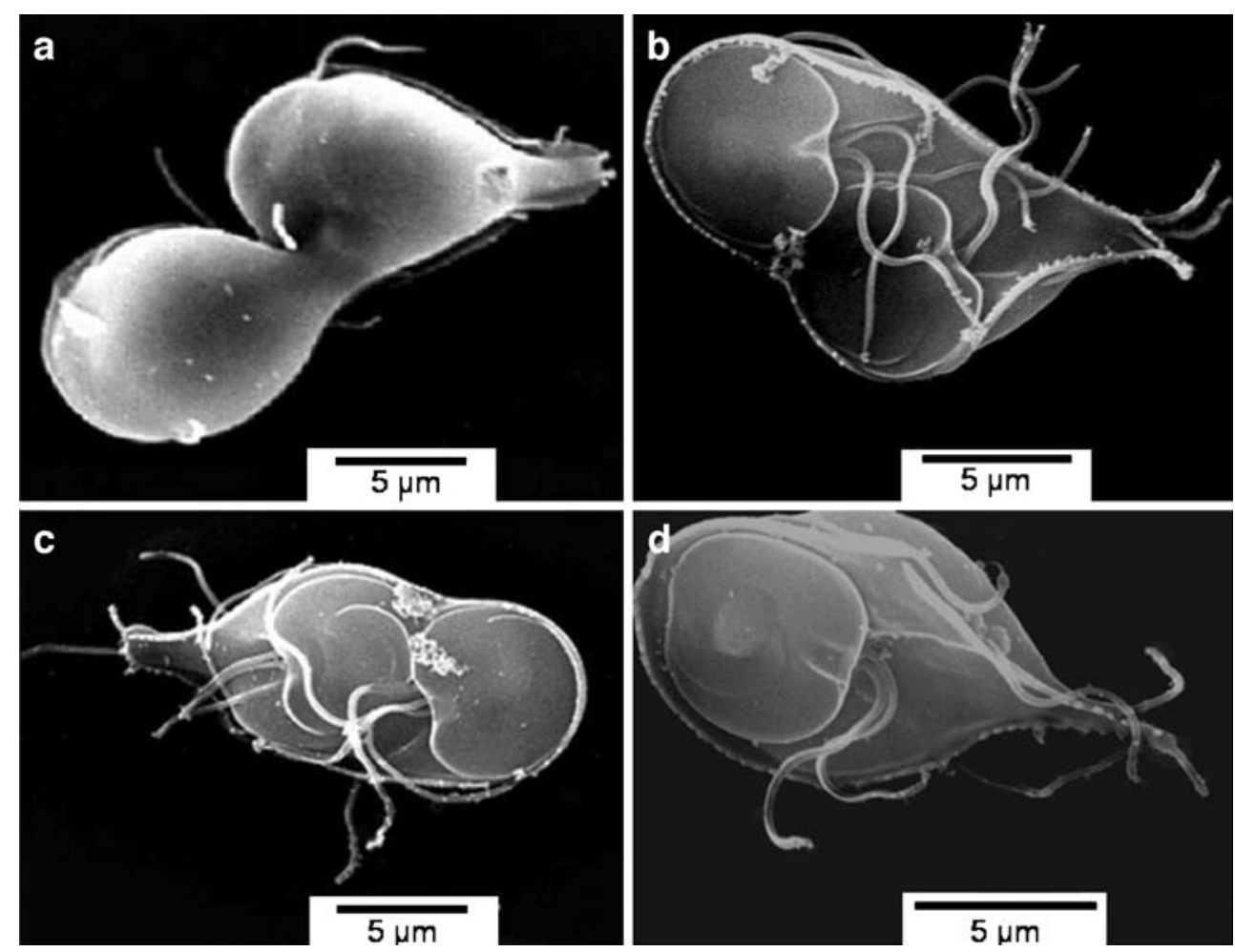

\section{Discussion}

Giardia trophozoites colonize the small intestine, and trophozoites rapidly take up arginine, which is converted to citrulline and then to ornithine, which is extruded in an arginine-ornithine antiport system (Knodler et al. 1995). Arginine depletion from the extracellular millieu downmodulates NO production by intestinal epithelial cells, comprising an escape mechanism (Eckmann et al. 2000). Furthermore, polyamines play a protective role in stress conditions (Jung et al. 2003; Rider et al. 2007). Therefore, the detailed understanding of the aminoacid/polyamine metabolism in Giardia can lead not only to the elucidation of giardiasis pathophysiology but also to the discovery of new chemotherapy targets.

Gillin et al. (1984) previously showed that growth inhibition by DFMO is reverted by addition of exogenous spermidine, but not putrescine and spermine, which were toxic to parasites. Little is known about the biological role of putrescine, spermidine, or spermine in this parasitic protozoan.

G. lamblia, ODC activity is significantly higher than that in $T$. vaginalis and E. histolytica, but these parasites present several-fold more putrescine than the former (Gillin et al. 1984). In Giardia, the putrescine and spermidine concentrations are nearly equimolar, whereas the other ones display remarkably higher diamine levels. The Giardia ODC activity is relatively low, compared with the arginine dihydrolase pathway (Schofield et al. 1992).
Moreover, putrescine may be recognized by the arginine transport system, possibly interfering with the arginineornithine antiport and significantly diminishes the arginine deiminase activity (Knodler et al. 1995). DAB may act in a similar way, diminishing the proliferation capacity of $G$. lamblia. This effect is presumably multifactorial, as parasite cytokinesis was both truncated and deregulated, and differentiation was also triggered. Polyamines are involved in mammalian cell nuclear division and cytokinesis (Sunkara et al. 1979; Knuutila and Pohjanpelto 1983), and their deprivation may lead to multinucleate Trypanosoma brucei (Bacchi et al. 1983) and mammalian cells (Sunkara et al. 1981; Kramer et al. 2001). The giardial cell division is accepted to be rather symmetrical (Ghosh et al. 2001; Sagolla et al. 2006), but diverse cell division patterns were also reported (Benchimol 2004a). These discrete results may be caused, at least in part, by different experimental conditions. It is noteworthy that under the conditions employed here, parasites generally divide rather symmetrically as previously reported, but many DAB-treated trophozoites were observed during asymmetrical cell divisions. The detection of impaired cytokinesis and asymmetrically dividing cells suggest that putrescine/polyamines regulate the parasite mitotic process, as reported in mammalian cells (Sunkara et al. 1983).

Polyamines were also shown to regulate cell differentiation in several cell types (Fernandez-Pinilla and Pestana 1987; Gavin et al. 2004; Pietila et al. 2005; Maeda et al. 2006). The encystment-specific vesicles (ESV) and clefts 
Fig. 3 After $24 \mathrm{~h}$ DAB treatment, trophozoites presented cytoplasmic clefts (a) and encystment-specific vesicles (b). Using SEM, we observed dorsal surface protrusions (c), presumably formed by the discharge of encystment-specific vesicles, and ventral disk internalization (d). Disassembly and internalization of flagella (e, arrows) and ventral disk cytoskeleton (f, $V D$ ) were detected after $72 \mathrm{~h}$. The formation of thin loose cyst walls (CW) was also observed $(\mathbf{e}, \mathbf{f})$
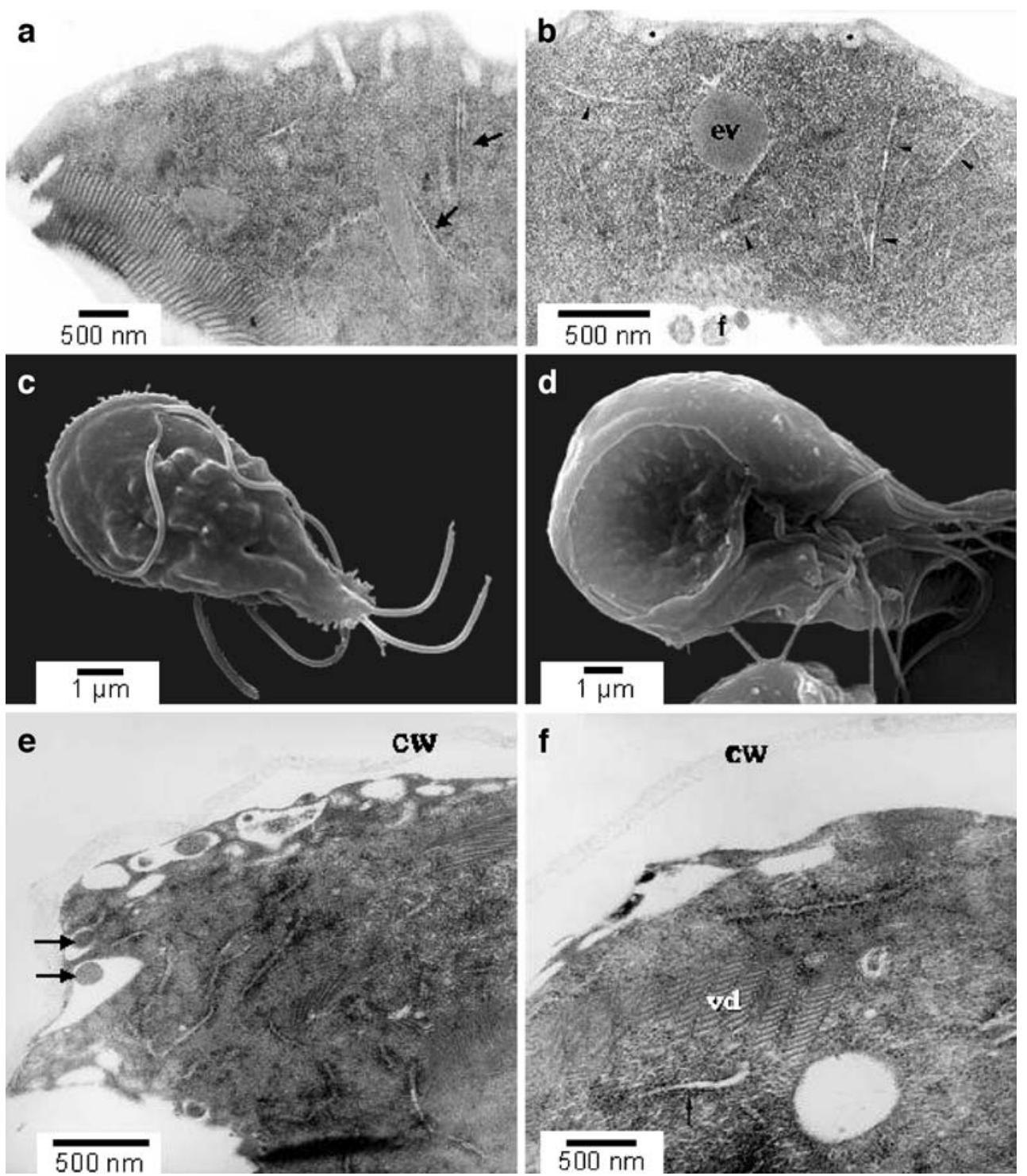

take part in the giardial secretory machinery that releases cyst wall components (Lanfredi-Rangel et al. 2003; Hehl and Marti 2004;). The surface protrusions detected by SEM in DAB-treated trophozoites were presumably formed by the fusion of ESV (Lanfredi-Rangel et al. 2003), discharging cell wall material at the transforming parasite surface, as reported previously (Benchimol 2004b). The observation of cytoplasmic clefts, ESV, and internalization of flagella and ventral disk as well as the formation of cyst walls indicate that DAB is an encystment-triggering agent.

Differentiation to cyst forms which are predominant in the jejunum is triggered by stimuli such as elevated $\mathrm{pH}$ and
Fig. 4 Detection of TBARS 1 mM DAB treatment significantly $(P<0.05$ - ANOVA and a posteriori Tuckey) enhanced lipid peroxidation, and this effect was partially reverted by $200 \mu \mathrm{M}$ aminoguanidine. Basal lipid peroxidation level (as in untreated control) were unaffected by aminoguanidine

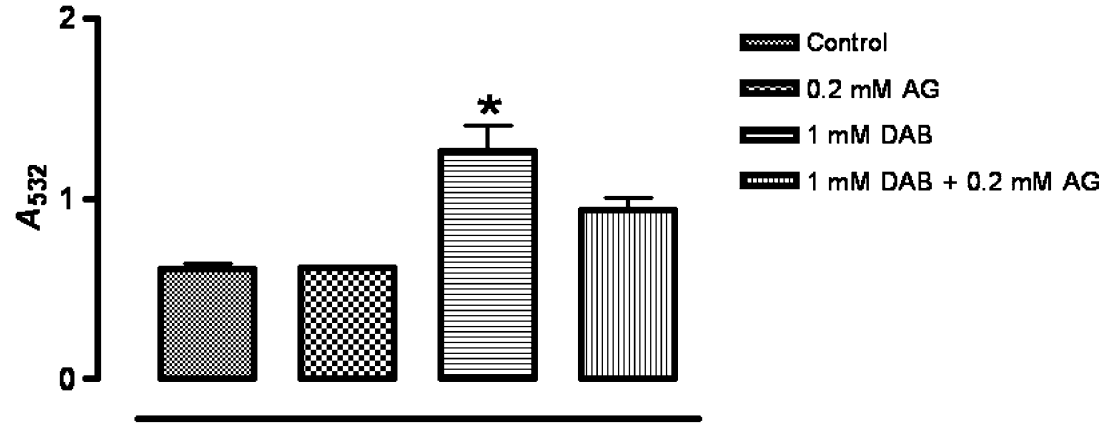

18 hours 
high bile concentration (Gillin et al. 1987; Schupp et al. 1988; Reiner et al. 1993; Campbell and Faubert 1994). ODC activity may regulate microbial differentiation, and DAB was reported to remarkably inhibit ODC activity in fungi (Martinez-Pacheco et al. 1989) and bacteria (Tkachenko et al. 2001). In this regard, the encystment process in Entamoeba invadens is associated with decreased ODC activity (Calvo-Méndez et al. 1993). Interestingly, DAB induced the formation of pseudocysts in $T$. foetus (unpublished observation).

Furthermore, as cysts are resistant forms, encystment may comprise a response to stress conditions (Luján et al. 1996). Although cyst viability was not evaluated, the fact that only a few cells formed cyst walls, and these were loose and thin as compared to normal cysts (e.g. ChávezMunguía et al. 2007), even employing optimal microscopy procedures, suggests that the encystment maybe not be effectively producing viable cysts.

We have previously noticed that DAB leads to the destruction of redox organelles such as the trichomonad hydrogenosomes (Reis et al. 1999) and trypanosomatid mitochondria (Menezes et al. 2006). Because polyamines (Tabor and Tabor 1984) and putrescine (Tkachenko and Nesterova 2003) display antioxidant activity, we decided to assess the oxidative stress using TBARS detection. The DAB-induced lipid peroxidation reported here may be due at least in part to diminished polyamine concentrations as reported in T. foetus (Reis et al. 1999). Besides down modulating polyamine transport/metabolism, DAB might be oxidized by amine oxidases present in the serum and/or the parasite, which catalyze the oxidation of biogenic amines, including polyamines to the corresponding aldehyde, with the release of $\mathrm{NH}_{3}$ and $\mathrm{H}_{2} \mathrm{O}_{2}$, leading to the increased lipid peroxidation (Agostinelli et al. 2004).

To approach the DAB prooxidant effects, we tested whether polyamine oxidation could be involved, using a well-known antagonist. The addition of $200 \mu \mathrm{M}$ aminoguanidine, a diamine/polyamine oxidase inhibitor, partially reverted the DAB (Fig. 4), but not the putrescine effects (not shown).

Aminoguanidine acts as an antioxidant in vivo, preventing the formation of oxygen-free radicals and lipoperoxides (Soška et al. 1997; Giardino et al. 1998). Therefore, aminoguanidine probably inhibits the DAB oxidation, reducing lipoperoxidation. In this regard, a polyamine oxidase activity was recently demonstrated in Toxoplasma gondii, a parasitic protozoan that also transports arginine and ornithine, which are metabolized via arginine dehydrolase pathway (Cook et al. 2007). In addition, DAB may be less effective than putrescine in protecting membranes, and as it is not metabolized as the native diamine, it is presumably accumulated, resulting in the prooxidant effect.
Taken together, these data indicate that the detailed understanding of polyamine biology in Giardia parasite will provide a new arsenal for therapeutic intervention.

Acknowledgments We acknowledge the valuable technical assistance of Claudio Pereira Figueira and secretarial assistance of Elisângela Sodré. WS, MFO, and MAVS are CNPq research fellows. All the experiments reported here comply with Brazilian laws and norms of the Health Ministry.

This study is supported by TDR, FIOCRUZ, CNPq, PROCAD/ CAPES, FAPESB.

\section{References}

Agostinelli E, Arancia G, Vedova LD, Belli F, Marra M, Salvi M, Toninello A (2004) The biological functions of polyamine oxidation products by amine oxidases: perspectives of clinical applications. Amino Acids 27:347-358

Ali SA, Hill DR (2003) Giardia intestinalis. Curr Opin Infect Dis 16:453-460

Bacchi CJ, Yarlett N (2002) Polyamine metabolism as chemotherapeutic target in protozoan parasites. Mini Rev Med Chem 2:553563

Bacchi CJ, Garofalo J, Mockenhaupt D, McCann PP, Diekema KA, Pegg AE, Nathan HC, Mullaney EA, Chunosoff L, Sjoerdsma A, Hutner SH (1983) In vivo effects of alpha-DL-difluoromethylornithine on the metabolism and morphology of Trypanosoma brucei brucei. Mol Biochem Parasitol 7:209-225

Bansal D, Malla N, Mahajan RC (2006) Drug resistance in amoebiasis. Indian J Med Res 123:115-118

Bellé NA, Dalmolin GD, Fonini G, Rubin MA, Rocha JB (2004) Polyamines reduces lipid peroxidation induced by different prooxidant agents. Brain Res 1008:245-251

Benchimol M (2004a) Mitosis in Giardia lamblia: multiple modes of cytokinesis. Protist 155:33-44

Benchimol M (2004b) The release of secretory vesicle in encysting Giardia lamblia. FEMS Microbiol Lett 235:81-87

Bendesky A, Menendez D, Ostrosky-Wegman P (2002) Is metronidazole carcinogenic? Mutat Res 511:133-144

Berkman DS, Lescano AG, Gilman RH, Lopez SL, Black MM (2002) Effects of stunting, diarrhoeal disease, and parasitic infection during infancy on cognition in late childhood: a follow-up study. Lancet 359:564-571

Calvo-Méndez C, Villagomez-Castro JC, Lopez-Romero E (1993) Ornithine decarboxylase activity in Entamoeba invadens. Int $\mathrm{J}$ Parasitol 23:847-852

Campbell JD, Faubert GM (1994) Comparative studies on Giardia lamblia encystation in vitro and in vivo. J Parasitol 80:36-44

Chávez-Munguía B, Omaña-Molina M, González-Lázaro M, GonzálezRobles A, Cedillo-Rivera R, Bonilla P, Martínez-Palomo A (2007) Ultrastructure of cyst differentiation in parasitic protozoa. Parasitol Res 100:1169-1175

Cook T, Roos D, Morada M, Zhu G, Keithly JS, Feagin JE, Wu G, Yarlett N (2007) Divergent polyamine metabolism in the Apicomplexa. Microbiology 153:123-130

Eckmann L, Laurent F, Langford TD, Hetsko ML, Smith JR, Kagnoff MF, Gillin FD (2000) Nitric oxide production by human intestinal epithelial cells and competition for arginine as potential determinants of host defense against the lumendwelling pathogen Giardia lamblia. J Immunol 164:14781487 
Farthing MJ (2002) Tropical malabsorption. Semin Gastrointest Dis 13:221-231

Fernandez-Pinilla R, Pestana A (1987) Role of polyamines in proliferation and differentiation of Dictyostelium discoideum as ascertained by difluoromethylornithine treatment. Rev Esp Fisiol 43:439-443

Gavin IM, Glesne D, Zhao Y, Kubera C, Huberman E (2004) Spermine acts as a negative regulator of macrophage differentiation in human myeloid leukemia cells. Cancer Res 64:74327438

Ghosh S, Frisardi M, Rogers R, Samuelson J (2001) How Giardia swim and divide. Infect Immun 69:7866-7872

Giardino I, Fard AK, Hatchell DL, Brownlee M (1998) Aminoguanidine inhibits reactive oxygen species formation, lipid peroxidation, and oxidant-induced apoptosis. Diabetes 47:1114 1120

Gillin FD, Reiner DS, McCann PP (1984) Inhibition of growth of Giardia lamblia by difluoromethylornithine, a specific inhibitor of polyamine biosynthesis. J Protozool 31:161-163

Gillin FD, Reiner DS, Gault MJ, Douglas H, Das S, Wunderlich A, Sauch JF (1987) Encystation and expression of cyst antigens by Giardia lamblia in vitro. Science 235:1040-1043

Goldman P (1980) Metronidazole: proven benefits and potential risks. Johns Hopkins Med J 147:1-9

Gorowara S, Ganguly NK, Mahajan RC, Walia BN (1992) Study on the mechanism of Giardia lamblia induced diarrhoea in mice. Biochim Biophys Acta 1138:122-126

Hehl AB, Marti M (2004) Secretory protein trafficking in Giardia intestinalis. Mol Microbiol 53:19-28

Jung IL, Oh TJ, Kim IG (2003) Abnormal growth of polyaminedeficient Escherichia coli mutant is partially caused by oxidative stress-induced damage. Arch Biochem Biophys 418:125-132

Keister DB (1983) Axenic culture of Giardia lamblia in TYI-S-33 medium supplemented with bile. Trans R Soc Trop Med Hyg 77:487-488

Knodler LA, Schofield PJ, Edwards MR (1995) L-arginine transport and metabolism in Giardia intestinalis support its position as a transition between the prokaryotic and eukaryotic kingdoms. Microbiology 141:2063-2070

Knuutila S, Pohjanpelto P (1983) Polyamine starvation causes parallel increase in nuclear and chromosomal aberrations in a polyaminedependent strain of CHO. Exp Cell Res 145:222-226

Kramer DL, Chang BD, Chen Y, Diegelman P, Alm K, Black AR, Roninson IB, Porter CW (2001) Polyamine depletion in human melanoma cells leads to G1 arrest associated with induction of $\mathrm{p} 21 \mathrm{WAF} 1 / \mathrm{CIP} 1 / \mathrm{SDI} 1$, changes in the expression of p21-regulated genes, and a senescence-like phenotype. Cancer Res 61:7754 7762

Lanfredi-Rangel A, Attias M, Reiner DS, Gillin FD, De Souza W (2003) Fine structure of the biogenesis of Giardia lamblia encystation secretory vesicles. J Struct Biol 143:153-163

Lemée V, Zaharia I, Nevez G, Rabodonirina M, Brasseur P, Ballet JJ, Favennec L (2000) Metronidazole and albendazole susceptibility of 11 clinical isolates of Giardia duodenalis from France. J Antimicrob Chemother 46:819-821

Lengerich EJ, Addiss DG, Juranek DD (1994) Severe giardiasis in the United States. Clin Infect Dis 18:760-763

Lloyd D, Ralphs JR, Harris JC (2002) Giardia intestinalis, a eukaryote without hydrogenosomes, produces hydrogen. Microbiology 148:727-733

Lujan HD, Mowatt MR, Byrd LG, Nash TE (1996) Cholesterol starvation induces differentiation of the intestinal parasite Giardia lamblia. Proc Natl Acad Sci USA 93:7628-7633

Maeda T, Wakasawa T, Shima Y, Tsuboi I, Aizawa S, Tamai I (2006) Role of polyamines derived from arginine in differen- tiation and proliferation of human blood cells. Biol Pharm Bull 29:234-239

Martinez-Pacheco M, Rodriguez G, Reyna G, Calvo-Mendez C, RuizHerrera J (1989) Inhibition of the yeast-mycelial transition and the phorogenesis of Mucorales by diamino butanone. Arch Microbiol 151:10-14

Menezes D, Valentim C, Oliveira MF, Vannier-Santos MA (2006) Putrescine analogue cytotoxicity against Trypanosoma cruzi. Parasitol Res 98:99-105

Muller S, Coombs GH, Walter RD (2001) Targeting polyamines of parasitic protozoa in chemotherapy. Trends Parasitol 17:242249

Nanda N, Michel RG, Kurdgelashvili G, Wendel KA (2006) Trichomoniasis and its treatment. Expert Rev Anti Infect Ther $4: 125-35$

Nash TE (2001) Treatment of Giardia lamblia infections. Pediatr Infect Dis J 20:193-195

Partovi F, Khalili G, Kariminia A, Mahmoudzadeh-Niknam H (2007) Effect of Giardia lamblia infection on the cognitive function of school children. Iranian J Publ Health 36:73-78

Petri WA Jr (2000) Protozoan parasites that infect the gastrointestinal tract. Curr Opin Gastroenterol 16:18-23

Pietila M, Pirinen E, Keskitalo S, Juutinen S, Pasonen-Seppanen S, Keinanen T, Alhonen L, Janne J (2005) Disturbed keratinocyte differentiation in transgenic mice and organotypic keratinocyte cultures as a result of spermidine/spermine $N$-acetyltransferase overexpression. J Invest Dermatol 124:596-601

Reiner DS, Hetsko ML, Das S, Ward HD, McCaffery M, Gillin FD (1993) Giardia lamblia: absence of cyst antigens and reduced secretory vesicle formation and bile salt uptake in an encystationdeficient subline. Exp Parasitol 77:461-472

Reis IA, Martinez MP, Yarlett N, Johnson PJ, Silva-Filho FC, VannierSantos MA (1999) Inhibition of polyamine synthesis arrests trichomonad growth and induces destruction of hydrogenosomes. Antimicrob Agents Chemother 43:1919-1923

Rider JE, Hacker A, Mackintosh CA, Pegg AE, Woster PM, Casero RA Jr (2007) Spermine and spermidine mediate protection against oxidative damage caused by hydrogen peroxide. Amino Acids 33:231-240

Sagolla MS, Dawson SC, Mancuso JJ, Cande WZ (2006) Threedimensional analysis of mitosis and cytokinesis in the binucleate parasite Giardia intestinalis. J Cell Sci 119:48894900

Savioli L, Smith H, Thompson A (2006) Giardia and Cryptosporidium join the 'Neglected Diseases Initiative'. Trends Parasitol 22:203208

Schofield PJ, Costello M, Edwards MR, O'Sullivan WJ (1990) The arginine dihydrolase pathway is present in Giardia intestinalis. Int J Parasitol 20:697-699

Schofield PJ, Edwards MR, Matthews J, Wilson JR (1992) The pathway of arginine catabolism in Giardia intestinalis. Mol Biochem Parasitol 51:29-36

Schupp DG, Januschka MM, Sherlock LA, Stibbs HH, Meyer EA, Bemrick WJ, Erlandsen SL (1988) Production of viable Giardia cysts in vitro: determination by fluorogenic dye staining, excystation, and animal infectivity in the mouse and Mongolian gerbil. Gastroenterology 95:1-10

Scott KG, Meddings JB, Kirk DR, Lees-Miller SP, Buret AG (2002) Intestinal infection with Giardia spp. reduces epithelial barrier function in a myosin light chain kinase-dependent fashion. Gastroenterology 123:1179-1190

Soška V, Olšovský J, Zechmeister A, Lojek A, Bouda J, Garcia Escamilla RM (1997) Free oxygen radicals and lipoperoxides in type II (non-insulino-dependent) diabetic patients. Revista Mexicana de Patologia Clinica 44:62-66 
Stimac E, Morris DR (1987) Messenger RNAs coding for enzymes of polyamine biosynthesis are induced during the G0-G1 transition but not during traverse of the normal G1 phase. J Cell Physiol 133:590-594

Sunkara PS, Rao PN, Nishioka K, Brinkley BR (1979) Role of polyamines in cytokinesis of mammalian cells. Exp Cell Res 119:63-68

Sunkara PS, Ramakrishna S, Nishioka K, Rao PN (1981) The relationship between levels and rates of synthesis of polyamines during mammalian cell cycle. Life Sci 28:1497-1506

Sunkara PS, Chang CC, Prakash NJ (1983) Role of polyamines during chromosome condensation of mammalian cells. Cell Biol Int Rep 7:455-465

Tabor CW, Tabor H (1976) 1,4-Diaminobutane (putrescine), spermidine, and spermine. Annu Rev Biochem 45:285-306

Tabor CW, Tabor H (1984) Polyamines. Annu Rev Biochem 53:749790
Taylor JL, Turo KA, McCann PP, Grossberg SE (1988) Inhibition of the differentiation of 3T3-L1 cells by interferon-beta and difluoromethyl ornithine. J Biol Regul Homeost Agents 2:99-104

Tkachenko AG, Nesterova LY (2003) Polyamines as modulators of gene expression under oxidative stress in Escherichia coli. Biochemistry (Mosc). 68:850-856

Tkachenko AG, Pshenichnov MR, Nesterova LY (2001) Putrescine as a oxidative stress protecting factor in Escherichia coli. Mikrobiologiia 70:487-494

Turrens JF (2004) Oxidative stress and antioxidant defenses: a target for the treatment of diseases caused by parasitic protozoa. Mol Aspects Med 25:211-220

Upcroft P, Upcroft JA (2001) Drug targets and mechanisms of resistance in the anaerobic protozoa. Clin Microbiol Rev $14: 150-164$

Yarlett N (1988) Polyamine biosynthesis and inhibition in Trichomonas vaginalis. Parasitol Today 4:357-360 